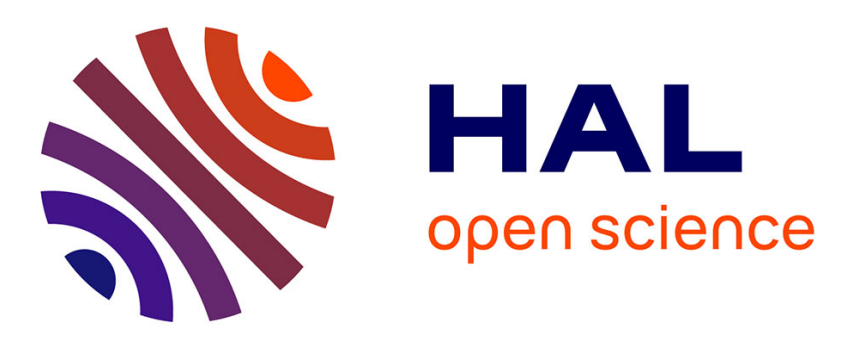

\title{
Borderline and schizotypal traits in college students : relationship and personality profiles
}

Henri Chabrol, Jonathan Bronchain, Martin Debbané, Jean Chassagne, Patrick Raynal

\section{- To cite this version:}

Henri Chabrol, Jonathan Bronchain, Martin Debbané, Jean Chassagne, Patrick Raynal. Borderline and schizotypal traits in college students: relationship and personality profiles. Bulletin of the Menninger Clinic, 2020, 84 (4), pp.299-318. 10.1521/bumc.2020.84.4.299 . hal-03192873

\section{HAL Id: hal-03192873 \\ https://hal.science/hal-03192873}

Submitted on 8 Apr 2021

HAL is a multi-disciplinary open access archive for the deposit and dissemination of scientific research documents, whether they are published or not. The documents may come from teaching and research institutions in France or abroad, or from public or private research centers.
L'archive ouverte pluridisciplinaire HAL, est destinée au dépôt et à la diffusion de documents scientifiques de niveau recherche, publiés ou non, émanant des établissements d'enseignement et de recherche français ou étrangers, des laboratoires publics ou privés. 
Borderline and Schizotypal Traits in College Students: Relationship and Personality Profiles Henri Chabrola $^{\mathrm{a}}, \mathrm{MD}, \mathrm{PhD}$, Jonathan Bronchain ${ }^{\mathrm{a}}$, $\mathrm{PhD}$ candidate, Martin Debbanéb ${ }^{\mathrm{PhD}}$, Jean Chassagne $^{\mathrm{a}}$, MA, Patrick Raynal ${ }^{\mathrm{a}}, \mathrm{PhD}$

${ }^{\text {a }}$ UFR de Psychologie, Université de Toulouse-Jean Jaurès, 5 allées Antonio Machado, 31058 Toulouse cedex 9, France

${ }^{b}$ Faculté de Psychologie et des Sciences de l'Education, Université de Genève, Boulevard du Pont d'Arve 4, 1205 Genève, Suisse

\section{Author Note}

Henri Chabrol, Professor of psychopathology (henri.chabrol@univ-tlse2.fr) Jonathan Bronchain, Graduate student (jonathan.bronchain@univ-tlse2.fr) Martin Debbané, Associate professor of developmental clinical psychology (martin.debbane@,unige.ch) Jean Chassagne, Master student (jean.chassagne@etu.univ-tlse2.fr) Patrick Raynal, Research scientist (patrick.raynal@inserm.fr),

*Corresponding author:

J. Bronchain, UFR de Psychologie, Université de Toulouse-Jean Jaurès, 5 allées Antonio Machado, 31058 Toulouse cedex 9

phone number: 33781533109

fax number: 33561257093

email: jonathan.bronchain@,univ-tlse2.fr 


\begin{abstract}
The relationships between borderline and schizotypal features are still debated. They frequently co-occur at trait and diagnostic levels. Studying personality profiles combining these traits might contribute to the identification of specific needs concerning treatment for distinct groups of young adults. Participants were 2341 college students who completed self-report questionnaires evaluating borderline traits, schizotypal traits and several psychopathological symptoms. A factor analysis was performed on borderline and schizotypal personality measures, leading to ten factors. Borderline factors were largely intercorrelated just as were schizotypal factors. Moreover, borderline factors were weakly to largely correlated to schizotypal factors. Five factors were very strongly correlated $(r>.50)$. Dissociation was strongly related to Odd Beliefs/Unusual Perceptive Experiences and Anxious-Depressive factors. Social Anxiety was strongly related to Suspiciousness. Based on these ten factors, a cluster analysis was conducted and resulted in four clearly distinct groups: a Low Traits cluster, a Narcissistic cluster, a Social Anxiety cluster, and a High Traits cluster. This High Traits cluster was characterized by homogeneously high levels of all factors, and high levels of internalizing and externalizing behaviors, suggesting that most college students with significant borderline traits also have high levels of schizotypal traits. This comorbidity needs to be taken into account in both clinical studies and practice.
\end{abstract}

Keywords: borderline traits, schizotypal traits, factor analysis, cluster analysis, college students 


\section{Introduction}

Borderline personality disorder (BPD) and schizotypal personality disorder (SPD) described two apparently distinct patterns of personality traits. BPD consists of a pattern of marked impulsivity and instability of affects, identity, and interpersonal relationships, whereas SPD is characterized by a pattern of odd speech and thinking, unusual perceptual experiences, eccentricities, social anxiety and discomfort with close relationships. However, historically, BPD and SPD were derived from "borderline states" describing patients at the boundary between neurosis and psychosis (Knight, 1953; Gunderson and Singer, 1975) before being separated in independent entities in the DSM-III (APA, 1980) and allocated to two different personality clusters, the cluster B (dramatic, overly emotional or unpredictable thinking or behavior) for BPD and the cluster A (odd, eccentric thinking or behavior) for SPD. Nevertheless, comorbidity is common, both at the categorical and dimensional levels, where BPD and SPD, on the one hand, schizotypal and borderline traits, on the other hand, frequently co-occur in clinical and community samples (Badoud et al., 2014; Baryshnikov et al., 2016; Pulay et al., 2009). In a community sample, BPD was most highly associated with SPD, out of DSM-IV personality disorders (Tomko et al., 2014). The relationships between these personality traits are particularly important to examine among young adults as personality disorders tend to have an onset in adolescence and to be established by young adulthood. Concerning BPD, symptom severity peaks between the ages of 20 and 29 years (e.g., Grant et al., 2008).

Among young adults, college students have been identified as a population at high risk for borderline symptoms and consequences. Although rates vary widely, the pooled prevalence of BPD in college samples was $11.6 \%$ (95\% CI 8.8-15.1) in recent studies conducted from 2008 to 2014 (Meaney et al., 2016a). Among college students, BPD is associated to high rates of self-harming and risky behaviors, anxious and depressive disorders, substance use, and interpersonal dysfunction (James and Taylor, 2007; Meaney et al., 2016b). Comorbid borderline and schizotypal traits may be 
linked to higher risk of difficulties in psychosocial functioning, reduced quality of life and problematic cannabis use (Chen et al., 2006; Raynal and Chabrol, 2016).

Moreover, both disorders would independently have a substantial impact on socialization and adaptation processes. Thus, information about these common deficits, usually associated with emotion dysregulation for borderline personality traits, and to cognitive specificity for schizotypal traits, may crucially inform the actual redefinition of psychiatric nosology. For example, the Research Domain Criteria project (RDoC; Insel et al., 2010) proposes to address this issue by identifying higher-level domains of human behavior and functioning (i.e., negative and positive valence systems, cognitive systems, social processes and arousal/regulatory systems) that provide a more comprehensive understanding of the nature of mental health and illness. More broadly, it is necessary to discuss the implications of a dimensional and transdiagnostic view of psychiatric disorders and to identify axis of dysfunction at play to promote the prevention and the effective treatments of comorbidities.

These concerns are also related to daily clinical practice where college counseling services are increasingly being called upon to provide treatment for students with BPD (Meaney-Tavares and Hasking, 2013; Pistorello et al., 2012; Uliaszek et al., 2016). It could be hypothesized that comorbid borderline and schizotypal traits may be linked to higher risk for treatment refusal and premature termination in psychotherapy because of suspiciousness and discomfort in close relationships. Early and effective intervention among college students might benefit from a better understanding of the association between borderline and schizotypal traits.

The only studies on the relationships between borderline and schizotypal traits among young adults using factor analysis have been conducted among college students. In a study of French female college students, an exploratory factorial analysis of the self-report Personality Disorder Questionnaire for DSM-IV (PDQ-4+; Hyler, 1994) extracted a four-factor solution possessing both 
satisfactory fit and meaningful interpretations. Borderline and schizotypal traits were the core components of the first factor (Chabrol et al., 2007). Fonseca-Pedrero et al. (2012) examined the relationship between schizotypal and borderline traits in a sample of college students by conducting a factorial analysis of the pooled items of two measures of those traits which highlighted the overlap of schizotypal and borderline traits. Raynal et al. (2016) conducted a cluster analytic study based on schizotypal dimensions, among a non-clinical sample of college students. It yielded a high schizotypy cluster characterized by high levels of all schizotypal dimensions and the highest level of borderline traits, confirming that schizotypal and borderline traits co-occur in a significant proportion of participants.

The aim of this exploratory study was to examine the relationships of schizotypal and borderline traits in a non-clinical sample of college students. This was first achieved by conducting an exploratory factorial analysis on both schizotypal and borderline traits, such as Fonseca-Pedrero et al.'s study. But we went further than Fonseca-Pedrero et al.'s (2012) study, using the extracted factors to explore the typology of college students by conducting a cluster analysis based on these factors. Cluster analyses may be useful to determine if there are subgroups of college students characterized by specific profiles of schizotypal and borderline traits and by various levels of comorbidity, in particular depressive symptoms, suicidal ideations, social anxiety, post-traumatic stress symptoms, substance use, and antisocial behaviors, which have been shown to be associated to borderline and schizotypal traits (e.g., Baryshnikov et al., 2016; Fonseca-Pedrero et al., 2012). At the theoretical level, cluster analyses may contribute to the debate about the relationships between schizotypal and borderline traits in young adults and inform about higher-order criteria likely to develop a transdiagnostic view of these two constructs. RDoC dimensions such as Social Processes (e.g., affiliation and attachment, perception and understanding of self and others) and Cognitive Systems (e.g., unusual perceptive experiences) could be common to these profiles, while others could 
differentiate them. At the level of clinical implications, a better knowledge of psychopathological profiles might contribute to the identification of specific needs concerning prevention or treatment for distinct groups of college students.

\section{Method}

\section{Participants and Procedure}

The data were collected through an online survey that was distributed to students from different French universities. The link was shared on social networks in groups specifically dedicated to students. Informed consent was obtained from all participants and they were informed that answers to the questionnaires would remain confidential. No compensation was offered to participate in the study and each participant had to confirm her/his student status. The participants were provided with the possibility to contact one of the authors $(\mathrm{PR})$ via email for further information or to receive referral to counseling. The study followed the guidelines of the Helsinki declaration and ethical issues of the current research were explored at a research meeting.

\section{Measures}

Borderline personality traits were measured using the Borderline Personality Inventory. The BPI is a 53-item self-report instrument developed by Leichsenring (1999). The BPI is based on Kernberg's concept of borderline personality organization (Kernberg, 1985). It explores a broad range of phenomenological manifestations of borderline symptomatology such as affectivity and identity disturbances, fear of closeness, interpersonal instability, self-mutilative/suicidal behavior, impulsive behavior, dissociative symptoms, and psychotic symptoms. Applying a modification of the original questionnaire which uses a true-false (yes-no) scale (Chabrol et al., 2004), items were rated on a Likert scale with seven levels of agreement ranging from "entirely false" (1) to "entirely true" (7), in order to optimize data for factorial analyses. The BPI yields a total score that is a dimensional measure of overall BPD psychopathology, with higher scores corresponding to greater BPD 
psychopathology (Leichsenring, 1999). Internal consistency and retest reliability proved to be satisfactory (Cronbach's $\alpha: 0.68-0.91, r_{\mathrm{tt}}: .73-.89$ ) while results for sensitivity were $0.85-0.89$, and for specificity were $0.78-0.89$ (Leichsenring, 1999).

Schizotypal personality traits were assessed using the French version of the Schizotypal Personality Questionnaire-Brief (SPQ-B), a self-administered scale including 22 items (Raine and Benishay, 1995; Raynal et al., 2016). Following Fonseca et al. (2012), we used a Likert-type response format and we chose the same rating scale as the BPI. Similarly to the BPI, a rating of six or seven was chosen for the symptom to be considered probably present. Schizotypal Personality Questionnaire showed adequate psychometric properties, and studies support the validity and utility of SPQ in cross-cultural research (Fonseca-Pedrero et al., 2018; Fonseca-Pedrero et al., 2017).

Depressive symptoms were measured with the 9-item Personality Health Questionnaire (PHQ-9; Kroenke et al., 2002). Suicidal ideations were assessed using the 3-item scale proposed by Garrison et al. (1991). Posttraumatic stress disorder was assessed using the 20-item Posttraumatic Stress Disorder Checklist for DSM-5 (PCL-5) (Paul et al., 2013). Dissociation was assessed using the 8-item Brief Dissociative Experiences Scale (DES-B) (Dalenberg and Carlson, 2010). Social anxiety was measured using the 3-item Mini-Social Phobia Inventory (Mini-SPIN) (Connor et al., 2001). Frequency of cannabis use was assessed with the scale used by Simons et al. (1998). Alcohol consumption was assessed using a similar scale. Antisocial behavior was measured using the Antisocial Behavior Scale (ABS; Schwab-Stone et al., 1999).

All the measures used in the current sample showed satisfactory psychometric properties with Cronbach's $\alpha$ ranging from .68 to .93 (Table 1).

\section{Analytic Plan}

Exploratory Factorial Analysis of Borderline and Schizotypal Traits 
The participants-to-items ratio $(2341: 76=31)$ was sufficient for exploratory factorial analysis. Bartlett's test of sphericity and the Kaiser-Meyer-Olkin measure of sampling adequacy were used to assess the factorability of the items. Exploratory factor analysis using principal axis factoring and varimax normalized rotation was used to examine the factor structure. Parallel analysis, which involves comparing eigenvalues from the observed data with those extracted from random data sets (500 for the current study) matched on number of cases and variables (Horn, 1965), was used to inform factor retention. The criteria for item inclusion were a factor loading of 0.40 or more a difference of at least 0.15 between the loading for this factor and any other loading.

\section{Cluster Analysis}

Cluster analysis was used to identify homogenous groupings of participants based on factor scores converted to z-scores. All variables had tolerance values $>.40$ excluding multicollinearity. In the first step, a hierarchical cluster analysis was conducted using Ward's method and squared Euclidean distance. Based on the dendrogram and the agglomeration schedule, the cluster solution was identified. In the second step, K-means clustering was used to assign individuals to one of the identified clusters. The proportions of males and females between clusters were compared with Fisher's exact test. Group differences between the clusters were tested using analyses of variance and Tukey's post-hoc tests.

\section{Results}

\section{Descriptive Statistics}

The sample consisted of 2341 participants, 1547 females (66\%) and 794 males (34\%) (mean age of females $=20.84 \pm 2.14$; mean age of males $=20.96 \pm 2.23$; age range $=18-30$ ), of which $1.68 \%$ of the data were previously excluded. Little's missing completely at random (MCAR) tests were performed for missing data. Multiple imputation and sensitivity analysis were conducted for data missing at random and non-ignorable data, respectively. These analyses did not bring any 
significant changes to our results. So, we should note that the results were maintained using the original unimputed dataset for all variables. As regards the participants' fields of study, $28 \%$ were studying social sciences, $14 \%$ law, $12 \%$ science or engineering, $12 \%$ art history, $9 \%$ literature, $9 \%$ economics, commerce, management or communication, $6 \%$ medicine or paramedical studies, $4 \%$ art or design, $2 \%$ education or pedagogy, $2 \%$ sport or exercise science, $1 \%$ history, geography or political science, and $1 \%$ were studying other subjects.

Mean BPI score of males (127.12 \pm 42.52$)$ was significantly higher than mean score of females $(123.29 \pm 42.89 ; t=-2.05, p=.04)$. Mean SPQ-B score of males $(76.81 \pm 23.45)$ was significantly higher than mean score of females $(72.39 \pm 24.76 ; t=4.16, p<.0001)$. Total scores of the BPI and SPQ-B were strongly correlated $(r=.74)$.

\section{Exploratory Factor Analysis of Borderline and Schizotypal Traits}

Barlett's test of sphericity $\left(\chi^{2}=74739,65, \mathrm{df}=2850, p<.001\right)$ and the Kaiser-Meyer Olkin value (.959) indicated that the items were appropriate for factor analysis. Parallel analysis supported a ten-factor solution. It explained $43 \%$ of the total variance. Among the 10 factors, 6 were composed of BPI items (Impulsivity, Anxious-depressive, Interpersonal Hypersensitivity, Identity Disturbance, Narcissistic, Dissociation), 3 of SPQ-B items (Social Anxiety, Suspiciousness, Eccentricity) and one consisting in both BPI and SPQ-B items (Odd Beliefs/Unusual Perceptive Experiences). The item loading for each factor is shown in Table 2.

Based on 708 meta-analytically derived correlations, Gignac and Szodorai (2016) established alternative effect size guidelines, where $r=0.10, r=0.20$, and $r=0.30$ were recommended as relatively small $\left(25^{\text {th }}\right.$ percentile $)$, medium $\left(50^{\text {th }}\right.$ percentile $)$, and relatively large $\left(75^{\text {th }}\right.$ percentile $)$, respectively. Using these guidelines, while all factors were significantly correlated, the effect sizes ranged from small to very large ( $r$ range: .08 - .57) (Table 3). Borderline factors ( $r$ range: $.34-.57)$ 
were largely intercorrelated just as were schizotypal factors ( $r$ range: $.37-.52$ ). Borderline factors were weakly to largely correlated to schizotypal factors ( $r$ range: .08 - .46).

\section{Cluster Analysis Based on Factor Scores}

The agglomeration schedule and dendrogram were used to identify the number of clusters. The agglomeration schedule showed a sudden increase in linkage distance (from 152.74 to 197.69) when four clusters merged to three clusters. This confirmed that the passage from four to three clusters would have more impact on the heterogeneity of the clusters than previous stages of the analysis. Therefore, the four-cluster solution was the most appropriate (Figure 1).

It consisted in a first group that had the lower levels of all factors, which was termed the Low Traits cluster ( $n=806$ [34\%]; females, 72\%; males, 28\%). A second group, that had a high level of narcissistic factor and moderate levels of the other factors, was named the Narcissistic cluster ( $n=$ 513 [22\%]; females, 52\%; males, 48\%). A third group picked on the social anxiety factor and had moderate levels of all other factors, with the exception of a low level of the narcissistic factor, and termed the Social Anxiety cluster ( $n=603$ [26\%]; females, 74\%; males, 26\%). A fourth group that had the highest levels of all traits that were at least greater than one SD above the Low traits cluster means. It was named the High Traits cluster ( $n=419$ [18\%]; females, 61\%; males, 39\%) (Table 1).

The proportions of males and females in the Low Traits cluster and the High Traits cluster were similar than in the total sample of users $(p=.09$ and $p=.22$, respectively). The proportion of males was higher in the Narcissistic cluster $(p=.04)$, and lower in the Social Anxiety cluster $(p=$ .03). A discriminant analysis showed clear discriminations among the four clusters, Wilks' $\lambda=.086, p$ $<.0001$, approximate $F(30,2293)=99.56$, with $96.2 \%$ of the original grouped cases correctly classified.

All clusters differed significantly from each other on almost all factor scores $(p<.0001)$ with the exception of the Narcissistic factor and the Intolerance to close relationship factor. The High 
Traits cluster had the lowest levels of academic achievement and the highest levels of internalizing behaviors (suicidal ideations, depressive symptoms, post-traumatic stress symptoms, dissociation) and externalizing behaviors (cannabis and alcohol use, and antisocial behaviors). The Social Anxiety cluster had low levels of academic achievement, intermediate levels of internalizing behaviors and the lowest levels of externalizing behaviors. The Narcissistic cluster displayed high levels of academic achievement, low levels of internalizing behaviors and intermediate levels of externalizing behaviors.

\section{Discussion}

We found self-reported borderline and schizotypal traits to be prevalent in a community sample of college students. In the present study, we found more borderline traits in males than females. However, previous studies in college populations have found that both males and females are equally likely to report borderline traits (Meaney et al., 2016). This discrepancy may be due to our use of the BPI measure to assess borderline personality traits. Previous studies have used the BPD questionnaire, which includes fewer items exploring impulsive behaviors. Levels of schizotypal traits were higher among males than females, similarly to Ma et al.'s (2010) study among college students.

Our results indicated an important association between self-reported borderline and schizotypal traits in a community sample of college students in accordance with the study by Badoud et al. (2014) who observed a strong correlation between the SPQ and the BPI $(r=.70)$ among nonclinical adolescents and with the study by Fonseca-Pedrero et al. (2012) who found a strong association $(r=.54)$ between the SPQ-B and the Borderline Personality Questionnaire (BPQ; Poreh et al., 2006) among non-clinical college students. As borderline and schizotypal traits were strongly associated, we conducted a factor analysis to extract the more independent dimensions from the pooled items of the BPI and SPQ-B. 


\section{Factor Structure of Borderline and Schizotypal Traits}

The factorial analysis of the pooled items of the BPI and SPQ-B yielded ten factors, 6 of them being composed of BPI items (Impulsivity, Anxious-depressive, Interpersonal Hypersensitivity, Identity Disturbance, Narcissistic, Dissociation), 3 of SPQ-B items (Social Anxiety, Suspiciousness, Eccentricity) and one consisting in both BPI and SPQ-B items (Odd Beliefs/Unusual perceptive experiences). These factors capture the main components of both borderline and schizotypal features. The six borderline factors closely resemble to the six-factor structure (Impulsivity, Instability in Interpersonal Relationships, Affectivity/Identity Disturbances, Narcissistic, Dissociation) extracted in non-clinical adolescents (Chabrol et al., 2004). This almost similarity between non-clinical adolescents and young adults may reflect shared developmental mechanisms in the transition period between childhood and adulthood. The schizotypal factors closely resemble to the 4 factors extracted from the SPQ-B in non-clinical college students by Raynal et al. (2016), negative schizotypy corresponding to Eccentricity, positive schizotypy to Odd Beliefs/Unusual Perceptive Experiences, reference ideas to Suspiciousness, and Social Anxiety being the same. However, this factor structure may reflect both the specificities of the self-report measures and the manifestation of borderline and schizotypal features among college students. For example, the greater number of borderline factors may reflect the greater number of BPI items compared to the SPQ-B.

The fact that all factors but one were composed of either borderline items or schizotypal items and that all factors had a high internal consistency suggest borderline and schizotypal dimensions are independent constructs. However, most borderline factors were moderately correlated to schizotypal factors, indicating that self-reported borderline and schizotypal traits are connected constructs. The only factor with overlapping items from the BPI and SPQ-B, Odd Beliefs/Unusual Perceptive Experiences, reflects the main overlap of symptoms between BPD and SPD. Cognitive-Perceptual distortions are one of the main dimensions of SPD (Raine and Benishay, 1995) whereas the 
susceptibility to transient impairment of reality testing, induced by intense emotional states or stress and manifested through cognitive and perceptual disorganization, has been considered as a core feature of BPD (Kernberg, 1985).

Our 10-factor structure showed both differences and convergences with the factor structure of schizotypal and borderline traits extracted by Fonseca-Pedrero et al. (2012) in a sample of college students. Fonseca et al. measured schizotypal and borderline traits using the SPQ-B and the Borderline Personality Questionnaire (BPQ; Poreh et al., 2006) and conducted a factorial analysis on SPQ-B and BPQ subscales scores. Three factors were retained: two borderline factors, named Identity/Interpersonal (Abandonment, Relationship, Self-image, Suicide and Emptiness) and deficit of control (Affective Instability, Intense Anger, and Impulsivity), and a mixed borderline and schizotypal factor composed of the Cognitive-Perceptual, Interpersonal, and Disorganized subscales of the SPQ-B and the quasi-psychotic states subscales of the BPQ. Both factor solutions were composed of moderately correlated factors, two factors out of three being borderline factors. In both factor solutions, unusual perceptual experiences and quasi-psychotic experiences were grouped in a mixed borderline and schizotypal factor.

\section{Cluster Analysis Based on Borderline and Schizotypal Factors}

Cluster analysis, based on dimensions of schizotypal and borderline symptoms yielded by factor analysis, was used to identify an empirically derived typology of college students. A hierarchical cluster analysis extracted a four-cluster solution. It consisted in a Low Traits cluster that had the lowest levels of all factors, a Narcissistic cluster which had moderate levels of all the other factors, a Social Anxiety cluster had moderate levels of all other factors, with the exception of a low level of the Narcissistic factor, and the High Traits cluster, consisting of $18 \%$ of the total sample, that had the highest levels of all schizotypal and borderline symptoms. This high schizotypal and borderline cluster showed that a significant proportion of this sample of college students displayed 
sub-clinical or a clinical level of both schizotypal and borderline traits. While schizotypal and borderline factors were moderately correlated in the total sample, cluster analysis revealed that these traits co-occur in a significant proportion of college students. This High Traits cluster was characterized by high homogeneous levels of all schizotypal and borderline factors with the exception of a peak on the dissociation factor.

Regarding RDoC domains (Cuthbert, 2014), the Negative Valence systems seem to highly contribute to the High Traits and Social Anxiety clusters which are both characterized by high levels of anxiety, depression, and suspiciousness. Conversely, the Positive Valence systems could be strongly involved in the Narcissistic, Impulsivity and Interpersonal Hypersensivity dimensions characterizing the High Traits cluster and, in part, the Narcissistic cluster.

The High Traits cluster had low academic achievement and high psychopathology: The high schizotypal and borderline cluster had the highest levels of suicidal ideations, depressive symptoms, post-traumatic stress symptoms, dissociation, cannabis and alcohol use, and antisocial behaviors. High scores observed in this cluster could be underpinned by a single latent trait referring to impairment in social functioning. According to Caspi et al. (2012), the vulnerability to a psychopathological disorder could be better understood by a bifactor model. This model would include a "p-factor", interpreted as a general factor of psychopathology, or a severity factor (Polek et al., 2018), and a higher order factor including internalization, externalization, and thought disorder. In this perspective, the High Traits cluster could represent a high p-factor group, explaining in part its high symptomatology on all evaluated dimensions.

The high levels of dissociation and post-traumatic stress symptoms in the High Traits cluster also reflect the complex relationships between dissociation, post-traumatic stress symptoms and borderline and schizotypal symptoms (Berenbaum et al., 2003; Korzekwa et al., 2009). Trauma may induce dissociation and post-traumatic stress symptoms mimicking borderline and schizotypal 
symptoms while borderline and schizotypal traits are vulnerability factors for post-traumatic distress (Steel et al., 2008). This High Traits cluster may have important clinical implications. As college counseling services are increasingly being called upon to provide treatment for students with BPD (Meaney-Tavares and Hasking, 2013; Pistorello et al., 2012; Uliaszek et al., 2016), therapists have to take into-account the therapeutic issues linked to the comorbidity of borderline and schizotypal symptoms and to the possible high level of dissociation. The co-occurrence of borderline and schizotypal symptoms may be linked to a higher risk for treatment refusal and premature termination in psychotherapy because of suspiciousness and discomfort in close relationships. The high level of dissociation displayed by individuals with comorbid borderline and schizotypal symptoms is a further therapeutic challenge as dissociation has a negative impact on therapeutic relationship and treatment outcome (Spitzer et al., 2007). Dissociation has been shown to predict poor response to dialectical behavioral therapy (DBT) in female patients with BPD (Kleindienst et al., 2011). As DBT is the most evaluated and recommended psychotherapy for college students with BPD (MeaneyTavares and Hasking, 2013; Lin et al., 2018; Pistorello et al., 2012, 2017; Uliaszek et al., 2016), future studies on DBT in college students or application of DBT to college students should consider the frequent association of borderline, schizotypal symptoms and dissociation.

The Narcissistic cluster and the Social Anxiety cluster may also have clinical implications. The Narcissistic cluster may reflect that narcissistic personality traits have increased among American college students over the generations reflecting cultural changes that may be worldwide (Twenge and Foster, 2010). This cluster was characterized by as high a level of academic achievement than the Low traits cluster. However, this cluster indicates that narcissistic features are associated with significant levels of psychopathology, more expressed in externalizing behaviors than in internalizing behaviors. We postulated that this Narcissistic cluster may point a group of college students, who make others suffer more than they suffer themselves, who have low rates of 
demand for psychotherapeutic treatment although they negatively impact the students' community functioning and social and emotional well-being.

The Social Anxiety cluster may reflect that social anxiety disorder is one of the most prevalent mental health problems experienced by college students today (e.g., Purdon et al., 2001). This cluster is also characterized by high levels of co-occurrent traits and symptoms, particularly suspiciousness, intolerance to close relationships, and depressive symptoms, that may contribute to lower psychotherapeutic demand and to alter the therapeutic relationship and the confidence in therapy effects.

\section{Conclusion and Implications for Practice}

In the context of RDoC redefinition of psychiatric nosology, our study brought important information on effective mean to differentiate profiles on schizotypal and borderline dimensions. Both Narcissism and Social Anxiety factors seem to be useful to distinguish our participants, while Odd beliefs/Unusual Perceptive Experience factor would be partially common to borderline and schizotypal traits. More specifically, and in RDoC terms, our clusters could be understood by various contributions of Negative and Positive Valence systems with some overlap on Cognitive Systems.

This study has several limitations. First, this study should be considered as exploratory and descriptive. Results are data-driven and may be not generalizable to a clinical sample since all participants were university students. Second, results might have been influenced by the questionnaires used to assess borderline and schizotypal traits. The SPQ-B is a brief instrument that does not explore all the SPD facets, in particular it does not include the anhedonia dimension, while the BPI does not specifically assess inappropriate, intense, and uncontrollable anger, and chronic feelings of emptiness which are DSM criteria for BPD. Moreover, the self-report of traits may have been influenced by impairment in self-reflection. No scales of desirability or infrequency were used. Third, although internet data collection methods, using online completion of self-report 
questionnaires from self-selected samples, are consistent with findings from traditional methods (Gosling et al., 2004), the possibility that participant self-selection may have biased the results cannot be excluded.

Despite these limitations, our study has several strengths such as large sample size $(N=2341)$ and the integration of a wide range of measures for external criteria and symptoms associated with borderline and schizotypal traits. Moreover, this study confirms the strong associations between selfreported borderline and schizotypal symptoms. Factor analysis of BPD and SPD symptoms revealed several distinct but connected dimensions. Although these dimensions were only moderately correlated, cluster analysis identified a subgroup characterized by homogeneously high levels of all these dimensions, and high levels of internalizing and externalizing behaviors. These results suggest that most college students with significant borderline symptoms also have high levels of schizotypal symptoms. This comorbidity may need to be taken into account in both clinical studies and practice. 


\section{References}

American Psychiatric Association (1980) Diagnostic and Statistical Manual of Mental Disorders (3 $3^{\text {rd }}$ Ed. Revised). Washington, DC: American Psychiatric Association.

Baryshnikov I, Suvisaari J, Aaltonen K, Koivisto M, Näätänen P, Karpov B, Paunio T (2016) Selfreported symptoms of schizotypal and borderline personality disorder in patients with mood disorders. Eur Psychiatry. 33:37-44.

Badoud D, Billieux J, Eliez S, Imhof A, Heller P, Eytan A, Debbané M (2015) Covariance and specificity in adolescent schizotypal and borderline trait expression. Early Interv Psychiatr. 9:378-387.

Berenbaum H, Valera EM, Kerns JG (2003) Psychological trauma and schizotypal symptoms. Schizophr Bull. 29:143-152.

Caspi A, Houts RM, Belsky DW, Goldman-Mellor SJ, Harrington H, Israel S, Moffitt TE (2014) The p factor: one general psychopathology factor in the structure of psychiatric disorders? Clin Psychol Sci. 2:119-137.

Chabrol H, Montovany A, Callahan S, Chouicha, K, Ducongé, E (2002) Factor analyses of the DIBR in adolescents. J Pers Disord. 16:374-384.

Chabrol H, Montovany A, Ducongé E, Kallmeyer A, Mullet E, Leichsenring F (2004) Factor structure of the borderline personality inventory in adolescents. Eur J Psychol Assess. 20:5965.

Chen H, Cohen P, Crawford TN, Kasen S, Johnson JG, Berenson K (2006) Relative impact of young adult personality disorders on subsequent quality of life: findings of a community-based longitudinal study. J Pers Disord. 20:510-523.

Connor KM, Kobak KA, Churchill LE, Katzelnick D, Davidson JRT (2001) Mini-SPIN : A brief screening assessment for generalized social anxiety disorder. Depress Anxiety. 14:137-140. 
Cuthbert, BN (2014) The RDoC framework: Facilitating transition from ICD/DSM to dimensional approaches that integrate neuroscience and psychopathology. World Psychiatry. 13(1), 2835.

Dalenberg C, Carlson, E (2010) New versions of the Dissociative Experiences Scale: The DES-R (Revised) and the DES-B (Brief). Paper presented at Annual Meeting of the International Society.

Fonseca-Pedrero, E, Debbané, M, Ortuño-Sierra, J, Chan, RCK, Cicero, DC, Zhang, LC, Brenner, C, et al. (2018) The structure of schizotypal personality traits: a cross-national study. Psychol. Med. 48(3), 451-462.

Fonseca-Pedrero, E, Lemos-Giraldez, S, Paino, M, Sierra-Baigrie, S, Muniz, J (2012). Relationship between schizotypal and borderline traits in college students. Span. J. Psychol. 15(1), 30614.

Fonseca-Pedrero, E, Ortuño-Sierra, J, Lucas-Molina, B, Debbané, M, Chan, RCK, Cicero, DC, et al. (2017) Brief assessment of schizotypal traits: A multinational study. Schizophr. Res. https://doi.org/10.1016/j.schres.2017.10.043

Horn JL (1965) A rationale and test for the number of factors in factor analysis. Psychometrika. 32:179-185.

Garrison CZ, Addy CL, Jackson KL, McKeown RE, Waller JL (1991) A longitudinal study of suicidal ideation in young adolescents. J Am Acad Child Adolesc Psychiatry. 30:597-603.

Gignac, G. E., \& Szodorai, E. T. (2016). Effect size guidelines for individual differences researchers. Personality and Individual Differences, 102,74-78.

Gosling SD, Vazire S, Srivastava S, John OP (2004) Should we trust Web-based studies? A comparative analysis of six preconceptions about Internet questionnaires. Am Psychol. 59:93104. 
Grant BF, Chou SP, Goldstein RB, Huang B, Stinson FS, Saha TD, Ruan WJ (2008) Prevalence, correlates, disability, and comorbidity of DSM-IV borderline personality disorder: results from the Wave 2 National Epidemiologic Survey on Alcohol and Related Conditions. J Clin Psychiatry. 69:533.

Gunderson JG, Singer MT (1975) Defining borderline patients: An overview. Am J Psychiatry. 132:1-10.

Insel T, Cuthbert B, Garvey M, Heinssen R, Pine DS, Quinn K, Sanislow C, Wang P (2010) Research Domain Criteria (RDoC): toward a new classification framework for research on mental disorders. Am J Psychiatry. 167:748-751.

James LM, Taylor J (2007) Impulsivity and negative emotionality associated with substance use problems and Cluster B personality in college students. Addict Behav. 32:714-727.

Kernberg OF (1985) Borderline conditions and pathological narcissism. Rowman \& Littlefield.

Kleindienst N, Limberger MF, Ebner-Priemer UW, Keibel-Mauchnik, J, Dyer A, Berger M, Bohus M (2011) Dissociation predicts poor response to dialectial behavioral therapy in female patients with borderline personality disorder. J Pers Disord. 25:432-447.

Knight RP (1953) Borderline states. Bull Menninger Clin. 17:1-12.

Korzekwa MI, Dell PF, Pain C (2009) Dissociation and borderline personality disorder: an update for clinicians. Curr Psychiatry Rep. 11:82-88.

Kroenke K, Spitzer RL, Williams JB (2001) The PHQ-9. J Gen Intern Med. 16:606-613.

Leichsenring F (1999) Development and first results of the Borderline Personality Inventory: A selfreport instrument for assessing borderline personality organization. J Pers Assess. 73:45-63.

Lin TJ, Ko HC, Wu JYW, Oei TP, Lane HY, Chen CH (2018) The effectiveness of dialectical behavior therapy skills training group vs. cognitive therapy group on reducing depression and 
suicide attempts for borderline personality disorder in Taiwan. Arch Suicide Res, (justaccepted).

Ma WF, Wu PL, Yang SJ, Cheng KF, Chiu HT, Lane HY (2010) Sensitivity and specificity of the Chinese version of the Schizotypal Personality Questionnaire-Brief for identifying undergraduate students susceptible to psychosis. Int J Nurs Stud. 47:1535-1544.

Meaney R, Hasking P, Reupert A (2016a) Prevalence of Borderline Personality Disorder in University Samples: Systematic Review, Meta-Analysis and Meta-Regression. PloS one. $11: \mathrm{e} 0155439$.

Meaney R, Hasking P, Reupert A (2016b) Borderline Personality Disorder symptoms in college students: The complex interplay between alexithymia, emotional dysregulation and rumination. PloS one. 11:e0157294.

Meaney-Tavares R, Hasking P (2013) Coping and regulating emotions: A pilot study of a modified dialectical behavior therapy group delivered in a college counseling service. J Am Coll Health. 61:303-309.

Paul F, Pommier de Santi V, Marimoutou C, Deparis X (2013) Validation de l'échelle PCLS et d'un auto-questionnaire court dans le cadre du dépistage des états de stress post-traumatiques chez les militaires de retour de mission. La Psychiatrie en Milieu Militaire. Toulon, Elsevier Masson.

Pistorello J, Fruzzetti AE, MacLane C, Gallop R, Iverson KM (2012). Dialectical behavior therapy (DBT) applied to college students: A randomized clinical trial. J Consult Clin Psychol. 80:982-994.

Pistorello J, Jobes D, Compton S, Locey NS, Walloch JC, Gallop R, Dickens Y (2017) Developing Adaptive Treatment Strategies to Address Suicidal Risk in College Students: A Pilot 
Sequential, Multiple Assignment, Randomized Trial (SMART). Arch Suicide Res, (justaccepted).

Polek E, Jones PB, Fearon P, Brodbeck J, Moutoussis M, Dolan R, Nspn Consortium (2018)

Personality dimensions emerging during adolescence and young adulthood are underpinned by a single latent trait indexing impairment in social functioning. BMC Psychiatry. 18:23.

Poreh AM, Rawlings D, Claridge G, Freeman JL, Faulkner C, Shelton C (2006) The BPQ: A scale for the assessment of borderline personality based on DSM-IV criteria. J Pers Disord. $20: 247-260$.

Pulay AJ, Stinson FS, Dawson DA, Goldstein RB, Chou SP, Huang, B, Saha TD, Sharon M. Smith SM, Roger P. Pickering RP, Ruan WJ, Hasin D, Grant BF (2009) Prevalence, correlates, disability, and comorbidity of DSM-IV schizotypal personality disorder: results from the wave 2 national epidemiologic survey on alcohol and related conditions. Prim Care Companion J Clin Psychiatry. 11:53-67.

Purdon C, Antony M, Monteiro S, Swinson RP (2001) Social anxiety in college students. J Anxiety Disord. 15:203-215.

Raine A, Benishay D (1995) The SPQ-B: a brief screening instrument for schizotypal personality disorder. J Pers Disord. 9:346-355.

Raynal P, Chabrol H (2016) Association between schizotypal and borderline personality disorder traits, and cannabis use in young adults. Addict Behav. 60:144-147.

Raynal P, Goutaudier N, Nidetch V, Chabrol H (2016) Typology of schizotypy in non-clinical young adults: Psychopathological and personality disorder traits correlates. Psychiatry Res. 246:182187.

Schwab-Stone M, Chen C, Greenberger E, Silver D, Voyce C (1999) No safe haven II: The effects of violence exposure on urban youth. J Am Acad Child Adolesc Psychiatry. 38:359-367. 
Simons J, Correia CJ, Carey KB, Borsari BE (1998) Validating a five-factor marijuana motives measure: Relations with use, problems, and alcohol motives. J Couns Psychol. 45:265-273.

Spitzer C, Barnow S, Freyberger HJ, Joergen Grabe H (2007) Dissociation predicts symptom-related treatment outcome in short-term inpatient psychotherapy. Aust N Z J Psychiatry. 41:682-687.

Steel C, Mahmood M, Holmes EA (2008) Positive schizotypy and trait dissociation as vulnerability factors for post-traumatic distress. Br J Clin Psychol. 47:245-249.

Tabachnick BG, Fidell LS (2007) Using multivariate statistics $\left(5^{\text {th }}\right.$ ed). Boston : Allyn and Bacon.

Tomko RL, Trull TJ, Wood PK, Sher KJ (2014) Characteristics of borderline personality disorder in a community sample: comorbidity, treatment utilization, and general functioning. J Pers Disord. 28:734-750.

Twenge JM, Foster JD (2010) Birth cohort increases in narcissistic personality traits among American college students, 1982-2009. Soc Psychol Personal Sci. 1:99-106.

Uliaszek AA, Rashid T, Williams GE, Gulamani T (2016) Group therapy for university students: A randomized control trial of dialectical behavior therapy and positive psychotherapy. Behav Res Ther. 77:78-85. 


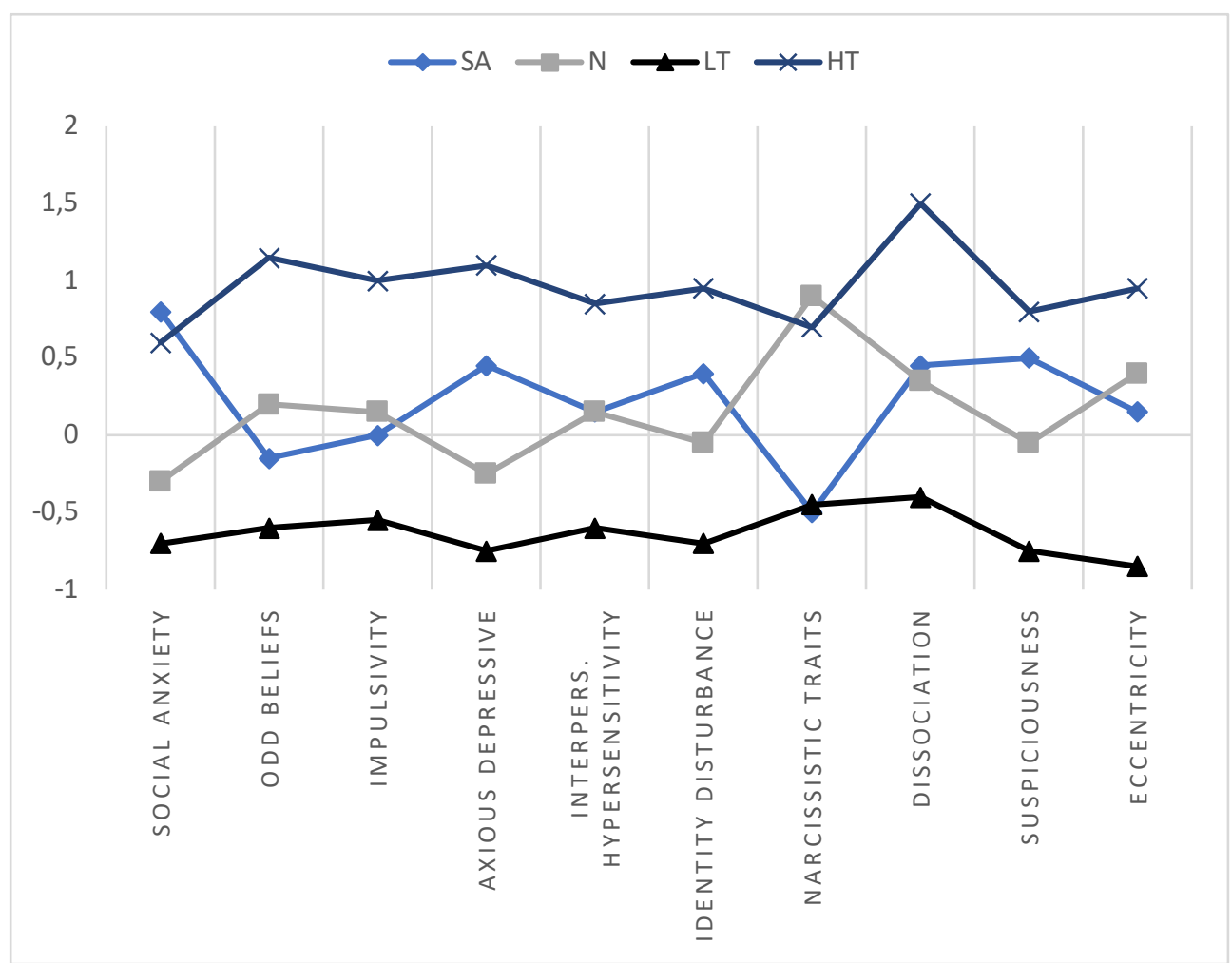

Figure 1. Cluster solution based on factor scores. SA: Social Anxiety cluster, N: Narcissistic cluster, LT: Low Traits cluster, HT: High Traits cluster. 
Table 1. Descriptive statistics $(N=2341)$ and cluster comparison using ANOVA and post-hoc tests

\begin{tabular}{|c|c|c|c|c|c|c|c|c|c|c|}
\hline & Sample & Min-Max & Alpha & MIC & \multicolumn{6}{|l|}{ Cluster $M(S D)$} \\
\hline & $\begin{array}{l}N=2341 \\
M(S D)\end{array}$ & & & & $\begin{array}{l}\text { Social anxiety } \\
n=603\end{array}$ & $\begin{array}{l}\text { Narcissistic } \\
n=513\end{array}$ & $\begin{array}{l}\text { Low traits } \\
n=806\end{array}$ & $\begin{array}{l}\text { High traits } \\
n=419\end{array}$ & $F$ & Significant comparisons \\
\hline Age & $22.73(12.03)$ & $18-30$ & n.a. & n.a. & $21.66(8.65)^{b}$ & $23.54(14.18)^{\mathrm{a}}$ & $23.83(14.41)^{\mathrm{a}}$ & $21.14(6.95)^{b}$ & $7.10^{*}$ & $\mathrm{~N}, \mathrm{LT}>\mathrm{SA}, \mathrm{HT}$ \\
\hline School level & $2.73(1.48)$ & $0-7$ & n.a. & n.a. & $2.67(1.48)^{\mathrm{b}}$ & $2.68(1.50)^{b}$ & $2.96(1.43)^{\mathrm{a}}$ & $2.43(1.47)^{\mathrm{c}}$ & $12.99 *$ & $\mathrm{LT}>\mathrm{SA}, \mathrm{N}>\mathrm{HT}$ \\
\hline Academic results & $3.05(1.06)$ & $1-5$ & n.a. & n.a. & $3(1.06)^{\mathrm{a}, \mathrm{b}}$ & $3.15(1.07)^{\mathrm{a}}$ & $3.09(1.03)^{\mathrm{a}}$ & $2.92(1.1)^{\mathrm{b}}$ & $4.49^{*}$ & $\mathrm{~N}, \mathrm{LT}>\mathrm{HT}$ \\
\hline Social anxiety & $6.11(3.06)$ & $0-12$ & 0.78 & 0.55 & $7.73(2.66)^{\mathrm{a}}$ & $4.93(2.84)^{\mathrm{c}}$ & $5.16(2.84)^{\mathrm{c}}$ & $7.04(2.97)^{b}$ & $141.78^{*}$ & $\mathrm{SA}>\mathrm{HT}>\mathrm{N}, \mathrm{LT}$ \\
\hline Dissociative symptomatology & $18.83(5.23)$ & $8-36$ & 0.72 & 0.25 & $19.62(4.57)^{b}$ & $18.93(4.44)^{\mathrm{c}}$ & $15.38(3.60)^{\mathrm{d}}$ & $24.2(4.99)^{\mathrm{a}}$ & $394.78^{*}$ & $\mathrm{HT}>\mathrm{SA}>\mathrm{N}>\mathrm{LT}$ \\
\hline Psychopathic traits & $33.39(6.69)$ & $17-60$ & 0.75 & 0.15 & $32.06(5.80)^{\mathrm{c}}$ & $36.42(6.21)^{b}$ & $30.24(5.53)^{d}$ & $37.64(6.72)^{\mathrm{a}}$ & $199.2 *$ & $\mathrm{HT}>\mathrm{N}>\mathrm{SA}>\mathrm{LT}$ \\
\hline Antisocial behavior & $4.80(4.05)$ & $0-18$ & 0.68 & 0.26 & $4.21(3.44)^{\mathrm{c}}$ & $5.54(4.21)^{\mathrm{b}}$ & $3.45(3.18)^{d}$ & $7.28(4.77)^{\mathrm{a}}$ & $101.78^{*}$ & $\mathrm{HT}>\mathrm{N}>\mathrm{SA}>\mathrm{LT}$ \\
\hline Schizotypal traits & $73.89(24.41)$ & $22-148$ & 0.90 & 0.29 & $89.79(15.49)^{b}$ & $73.7(14.11)^{\mathrm{c}}$ & $49.69(12.67)^{\mathrm{d}}$ & $102.13(16.33)^{\mathrm{a}}$ & $1450.35^{*}$ & $\mathrm{HT}>\mathrm{SA}>\mathrm{N}>\mathrm{LT}$ \\
\hline Cognitive perception dimension & $14.12(6.52)$ & $5-35$ & 0.68 & 0.29 & $14.45(5.24)^{\mathrm{b}}$ & $15.13(5.83)^{b}$ & $9.51(4.13)^{\mathrm{c}}$ & $21.28(5.46)^{\mathrm{a}}$ & $508.28^{*}$ & $\mathrm{HT}>\mathrm{SA}, \mathrm{N}>\mathrm{LT}$ \\
\hline Disorganized dimension & $27.82(10.43)$ & $8-56$ & 0.81 & 0.35 & $31.12(7.34)^{b}$ & $29.29(7,01)^{\mathrm{c}}$ & $17.68(5.59)^{\mathrm{d}}$ & $39.34(7.09)^{\mathrm{a}}$ & $1132.48^{*}$ & $\mathrm{HT}>\mathrm{SA}>\mathrm{N}>\mathrm{LT}$ \\
\hline Interpersonal dimension & $31.95(11.61)$ & $9-63$ & 0.84 & 0.40 & $40.22(8.41)^{\mathrm{a}}$ & $29.28(8.34)^{b}$ & $22.5(7.23)^{\mathrm{c}}$ & $41.5(9.75)^{\mathrm{a}}$ & $755.09^{*}$ & $\mathrm{HT}, \mathrm{SA}>\mathrm{N}>\mathrm{LT}$ \\
\hline Borderline personality traits & $124.59(42.80)$ & $50-294$ & 0.93 & 0.21 & $130.2(23.53)^{\mathrm{b}}$ & $125.34(23.34)^{\mathrm{c}}$ & $85.49(17.79)^{\mathrm{d}}$ & $190.81(28.13)^{\mathrm{a}}$ & $2008.9^{*}$ & $\mathrm{HT}>\mathrm{SA}>\mathrm{N}>\mathrm{LT}$ \\
\hline Depressive symptomatology & $9.47(5.38)$ & $0-27$ & 0.83 & 0.36 & $11.31(5.10)^{\mathrm{b}}$ & $8.55(4.19)^{\mathrm{c}}$ & $6.29(3.82)^{d}$ & $14.07(5.3)^{\mathrm{a}}$ & $316.36^{*}$ & $\mathrm{HT}>\mathrm{SA}>\mathrm{N}>\mathrm{LT}$ \\
\hline Suicidal ideation & $0.83(1.63)$ & $0-9$ & 0.85 & 0.67 & $1(1.68)^{b}$ & $0.58(1.24)^{\mathrm{c}}$ & $0.23(0.75)^{d}$ & $2.03(2.38)^{\mathrm{a}}$ & $137.21^{*}$ & $\mathrm{HT}>\mathrm{SA}>\mathrm{N}>\mathrm{LT}$ \\
\hline Post-traumatic stress disorder & $27.91(17.94)$ & $0-80$ & 0.93 & 0.39 & $33.97(15.7)^{b}$ & $25.38(14.60)^{\mathrm{c}}$ & $16.34(13.15)^{\mathrm{d}}$ & $44.56(16.00)^{\mathrm{a}}$ & $385.59^{*}$ & $\mathrm{HT}>\mathrm{SA}>\mathrm{N}>\mathrm{LT}$ \\
\hline Alcohol consumption & $3.15(2.07)$ & $0-8$ & n.a. & n.a. & $2.86(2.20)^{b}$ & $3.34(1.94)^{\mathrm{a}}$ & $3.08(2.06)^{b}$ & $3.47(1.99)^{\mathrm{a}}$ & $9.13^{*}$ & HT, N $>$ SA,LT \\
\hline Cannabis use & $0.82(1.81)$ & $0-8$ & n.a. & n.a. & $0.53(1.41)^{\mathrm{b}}$ & $1.1(2.05)^{\mathrm{a}}$ & $0.48(1.30)^{\mathrm{b}}$ & $1.57(2.47)^{\mathrm{a}}$ & $44.91^{*}$ & $\mathrm{HT}, \mathrm{N}>\mathrm{SA}, \mathrm{LT}$ \\
\hline F1- Social anxiety & $10.73(7.35)$ & $5-35$ & 0.82 & 0.44 & $25.06(4.77)^{\mathrm{a}}$ & $17.22(5.55)^{\mathrm{c}}$ & $14.2(5.09)^{\mathrm{d}}$ & $23.23(6.79)^{b}$ & $158.34 *$ & $\mathrm{SA}>\mathrm{HT}>\mathrm{N}>\mathrm{LT}$ \\
\hline F2- Unusual perceptual experiences & $16.03(8.77)$ & $7-49$ & 0.77 & 0.30 & $14.81(6.70)^{\mathrm{c}}$ & $17.02(7.74)^{b}$ & $10.38(4.24)^{\mathrm{d}}$ & $25.71(8.9)^{\mathrm{a}}$ & $156.89^{*}$ & $\mathrm{HT}>\mathrm{N}>\mathrm{SA}>\mathrm{LT}$ \\
\hline F3- Impulsiveness & $8.78(4.73)$ & $5-32$ & 0.69 & 0.31 & $10.45(3.08)^{\mathrm{c}}$ & $11.68(4.87)^{\mathrm{b}}$ & $8.12(3.15)^{d}$ & $16.11(5.64)^{\mathrm{a}}$ & $111.95^{*}$ & $\mathrm{HT}>\mathrm{N}>\mathrm{SA}>\mathrm{LT}$ \\
\hline F4- Anxiety-depressive & $25.64(9.55)$ & $8-54$ & 0.80 & 0.34 & $29.63(7.99)^{b}$ & $23.34(6.88)^{\mathrm{c}}$ & $17.39(6.10)^{\mathrm{d}}$ & $36.97(7.29)^{\mathrm{a}}$ & $275.42 *$ & $\mathrm{HT}>\mathrm{SA}>\mathrm{N}>\mathrm{LT}$ \\
\hline F5- Interpersonal hypersensitivity & $8.07(4.98)$ & $3-21$ & 0.81 & 0.6 & $8.62(4.31)^{b}$ & $8.68(4.30)^{b}$ & $5.07(2.69)^{\mathrm{c}}$ & $12.5(4.69)^{\mathrm{a}}$ & $110.69^{*}$ & $\mathrm{HT}>\mathrm{N}, \mathrm{SA}>\mathrm{LT}$ \\
\hline F6- Identity trouble & $10.01(4.24)$ & $3-21$ & 0.63 & 0.37 & $11.44(3.53)^{b}$ & $9.3(3.55)^{\mathrm{c}}$ & $6.78(2.72)^{\mathrm{d}}$ & $14.22(3.6)^{\mathrm{a}}$ & $171.65^{*}$ & $\mathrm{HT}>\mathrm{SA}>\mathrm{N}>\mathrm{LT}$ \\
\hline F7- Narcissistic traits & $6.15(3.37)$ & $2-14$ & n.a. & 0.46 & $5.05(2.32)^{b}$ & $9.47(2.60)^{\mathrm{a}}$ & $4.78(2.50)^{\mathrm{b}}$ & $9.37(3.08)^{\mathrm{a}}$ & $197.29^{*}$ & $\mathrm{~N}, \mathrm{HT}>\mathrm{SA}, \mathrm{LT}$ \\
\hline F8- Dissociation & $12.98(7.29)$ & $7-48$ & 0.82 & 0.40 & $13.01(5.23)^{b}$ & $11.58(4.33)^{\mathrm{c}}$ & $8.23(2.19)^{d}$ & $23.33(8.05)^{\mathrm{a}}$ & $297.3^{*}$ & $\mathrm{HT}>\mathrm{SA}>\mathrm{N}>\mathrm{LT}$ \\
\hline F9- Suspicion & $6.9(3.52)$ & $2-21$ & n.a. & 0.50 & $8.79(3.06)^{b}$ & $6.52(2.80)^{\mathrm{c}}$ & $4.18(2.20)^{\mathrm{d}}$ & $9.66(3.00)^{\mathrm{a}}$ & $157.03^{*}$ & $\mathrm{HT}>\mathrm{SA}>\mathrm{N}>\mathrm{LT}$ \\
\hline F10- Eccentricity & $10.58(4.92)$ & $3-21$ & 0.80 & 0.57 & $11.97(4.03)^{\mathrm{c}}$ & $13.2(4.14)^{b}$ & $7.62(3.29)^{\mathrm{d}}$ & $15.57(3.98)^{\mathrm{a}}$ & $152.96^{*}$ & $\mathrm{HT}>\mathrm{N}>\mathrm{SA}>\mathrm{LT}$ \\
\hline
\end{tabular}

MIC: average inter-item correlation; n.a.: not applicable

SA: Social Anxiety cluster; N: Narcissistic cluster; LT: Low Traits cluster; HT: High Traits cluster $* p<0.05$. 
Table 2. Factor loadings and internal consistencies of the 10 factors based on BPI (B) and SPQ-B (S) items

\begin{tabular}{|c|c|c|c|c|c|c|c|c|c|c|}
\hline \multirow[t]{2}{*}{ Items } & \multicolumn{10}{|c|}{ Factor loadings } \\
\hline & $\begin{array}{c}1 \\
\text { Social } \\
\text { anxiety } \\
\end{array}$ & $\begin{array}{c}2 \\
\text { Odd } \\
\text { beliefs }\end{array}$ & $\begin{array}{c}3 \\
\text { Impul- } \\
\text { sivity }\end{array}$ & $\begin{array}{c}4 \\
\text { Anx- } \\
\text { dep. }\end{array}$ & $\begin{array}{c}5 \\
\text { Interper. } \\
\text { Hypersens. }\end{array}$ & $\begin{array}{c}6 \\
\text { Ident. } \\
\text { disturb. }\end{array}$ & $\begin{array}{c}7 \\
\text { Narciss. }\end{array}$ & $\begin{array}{c}8 \\
\text { Dissoc. }\end{array}$ & $\begin{array}{c}9 \\
\text { Suspicious. }\end{array}$ & $\begin{array}{c}10 \\
\text { Eccent. }\end{array}$ \\
\hline S21. Uneasy talking to people I do not know well & .80 & & & & & & & & & \\
\hline S11. Uncomfortable in social situations involving unfamiliar people & .76 & & & & & & & & & \\
\hline S15. Keep in the background on social occasions & .74 & & & & & & & & & \\
\hline S18. Unable to get "close" to people & .41 & & & & & & & & & \\
\hline S22. Keep my feelings to myself & .41 & & & & & & & & & \\
\hline S12. Experiences with astrology, UFOs, ESP or a sixth sense & & .68 & & & & & & & & \\
\hline S2. Sense that some person or force is around you & & .67 & & & & & & & & \\
\hline B26. Has wrongly felt someone's presence & & .66 & & & & & & & & \\
\hline B22. Intense religious experiences & & .53 & & & & & & & & \\
\hline B24. May feel a special sense of destiny & & .49 & & & & & & & & \\
\hline B7. Visual hallucinations & & .48 & & & & & & & & \\
\hline S5. Common event or object that seemed to be a special sign for you & & .43 & & & & & & & & \\
\hline B30. Frequent use of drug & & & .64 & & & & & & & \\
\hline B45. Substance addiction & & & .61 & & & & & & & \\
\hline B51. Has been in trouble with the law & & & .45 & & & & & & & \\
\hline B4. Frequent risk taking & & & .43 & & & & & & & \\
\hline B47. Has often stolen & & & .42 & & & & & & & \\
\hline B33. Feels like being falling appart & & & & .63 & & & & & & \\
\hline B10. Feeling worthless or hopeless & & & & .60 & & & & & & \\
\hline B1. Frequent panic spells & & & & .57 & & & & & & \\
\hline B2. Lack of emotional response & & & & .45 & & & & & & \\
\hline B20. Self-mutilsation & & & & .42 & & & & & & \\
\hline B29. May fell others out to get him/her & & & & .42 & & & & & & \\
\hline B3. Often wonders who really is & & & & .41 & & & & & & \\
\hline B38. Frequent frightening dreams & & & & .40 & & & & & & \\
\hline B25. Feels trapped in close relationship & & & & & .78 & & & & & \\
\hline B28. Needs to break off close relationships & & & & & .72 & & & & & \\
\hline B23. Uncertain expectancies in love affairs & & & & & .55 & & & & & \\
\hline B42. Often doesn't know what really wants & & & & & & .51 & & & & \\
\hline B49. Undecided about politics, religion, morals & & & & & & .51 & & & & \\
\hline S13. I sometimes use words in unusual ways & & & & & & .42 & & & & \\
\hline B32. Feels being special & & & & & & & .61 & & & \\
\hline B31. Enjoy control over someone & & & & & & & .54 & & & \\
\hline B37. May feel body or part of it disappearing & & & & & & & & .58 & & \\
\hline B8. May feel people and things are not real & & & & & & & & .56 & & \\
\hline B27. Part of or whole body feels altered & & & & & & & & .52 & & \\
\hline B16. Feeling being directed & & & & & & & & .51 & & \\
\hline B21. Wrongly feels appearances change & & & & & & & & .51 & & \\
\hline B46. Feels in a dream or watching self in a film & & & & & & & & .51 & & \\
\hline B6. May feel someone else in him/her & & & & & & & & .45 & & \\
\hline S7. I feel I have to be on my guard even with friends & & & & & & & & & .51 & \\
\hline S17. Have to keep an eye out to stop people from taking advantage of you & & & & & & & & & .44 & \\
\hline S6. People think that I am a very bizarre person & & & & & & & & & & .64 \\
\hline S19. I am an odd, unusual person & & & & & & & & & & .56 \\
\hline S3. People comment on my unusual mannerisms and habits & & & & & & & & & & .55 \\
\hline Eigenvalues & 17.34 & 3.85 & 2.77 & 2.57 & 2.00 & 1.72 & 1.62 & 1.45 & 1.35 & 1.34 \\
\hline Cronbach's alpha $(\alpha)$ & .82 & .77 & .69 & .80 & .81 & .63 & n.a. & .82 & n.a. & .80 \\
\hline
\end{tabular}


Table 3. Intercorrelations Between Factor Scores

\begin{tabular}{lccccccccc}
\hline & 1 & 2 & 3 & 4 & 5 & 6 & 7 & 8 & 9 \\
1. Social anxiety & & & & & & & & & \\
2. Odd beliefs & $.18^{*}$ & & & & & & & & \\
3. Impulsivity & $.19^{*}$ & $.30^{*}$ & & & & & & & \\
4. Anxious-depressive & $.44^{*}$ & $.40^{*}$ & $.46^{*}$ & & & & & & \\
5. Interpersonal hypersensitivity & $.32^{*}$ & $.24^{*}$ & $.33^{*}$ & $.34^{*}$ & & & & & \\
6. Identity disturbance & $.35^{*}$ & $.29^{*}$ & $.35^{*}$ & $.49^{*}$ & $.39^{*}$ & & & & \\
7. Narcissitic traits & $.08^{*}$ & $.29^{*}$ & $.29 *$ & $.17^{*}$ & $.27^{*}$ & $.20^{*}$ & & & \\
8. Dissociation & $.31^{*}$ & $.56^{*}$ & $.43^{*}$ & $.57^{*}$ & $.39^{*}$ & $.46^{*}$ & $.28^{*}$ & & \\
9. Suspiciousness & $.52^{*}$ & $.36^{*}$ & $.24^{*}$ & $.46^{*}$ & $.35^{*}$ & $.34^{*}$ & $.22^{*}$ & $.39^{*}$ & \\
10. Eccentricity & $.37^{*}$ & $.41^{*}$ & $.36^{*}$ & $.43^{*}$ & $.30^{*}$ & $.36^{*}$ & $.39^{*}$ & $.45^{*}$ & $.43^{*}$ \\
\hline$* p<.01$ & & & & & & & & &
\end{tabular}

